\title{
Khảo sát tiềm năng kháng khuẩn từ cao chiết lá cây ổi (Psidium guajava $\mathbf{L}$.) \\ Evaluating the potential antibacterial activities of extracts from the leaves of (Psidium guajava $\mathrm{L}$.)
}

\author{
Dương Nhật Linh ${ }^{1 *}$, Nguyễn Tấn Phát ${ }^{2}$, Nguyễn Đoàn Thanh Liêm ${ }^{1}$, Trần Thị Á Ni ${ }^{3}$, \\ Nguyễn Thanh Duy ${ }^{4}$, Nguyễn Văn Minh ${ }^{1}$ \\ ${ }^{1}$ Trường Đại học Mở Thành phố Hồ Chí Minh, Việt Nam \\ ${ }^{2}$ Viện Hàn lâm Khoa học và Công nghệ Việt Nam, Việt Nam \\ ${ }^{3}$ Công ty TNHH MIDOLI, Việt Nam \\ ${ }^{4}$ Đại học San Francisco, Hoa Kỳ \\ *Tác giả liên hệ, Email: linh.dn@ ou.edu.vn
}

THÔNG TIN

DOI: $10.46223 / \mathrm{HCMCOUJS.}$ tech.vi.14.1.436.2019

Ngày nhận: 03/04/2019

Ngày nhận lại: 08/07/2019

Duyệt đăng: 17/09/2019

Tù khóa:

cây ổi, cao chiết, kháng khuẩn, MRSA

\section{TÓM TẮT}


alternative sources because of their safety with no or little side effects. In addition, plant compounds affect different targets on bacterial cells, so there is little risk of drug resistance. Particularly, Psidium guajava $\mathrm{L}$. is rich in antioxidants, vitamins C, potassium and fiber. Pharmacological studies have shown that the extracts from parts of guava plants had the antibacterial ability, healing the mucosa and stopping diarrhea. In this study, the extract ethyl acetate from guava leaves had the highest anti-bacteria and resistance against MRSA $(31.67 \pm 1.52 \mathrm{~mm})$. Ethyl acetate extract had an inhibitory effect on MRSA, E. coli and Salmonella typhi at a minimum inhibitory concentration (MIC) of 1/128 which corresponds to a concentration of $1.5625 \mathrm{mg} / \mathrm{mL}$ and the extract also had an inhibitory effect on $P$. aeruginosa at a MIC value of $1 / 256$ which corresponds to a concentration of $0.78 \mathrm{mg} / \mathrm{mL}$. By combining column chromatography and thin-layer chromatography methods, we isolated and refined PG01 with the highest MRSA resistance. Based on ${ }^{1} \mathrm{H}-\mathrm{NRM}$ and ${ }^{13} \mathrm{C}-\mathrm{NMR}$ spectroscopic data, the result showed that the structure of the compound with a strong antimicrobial ability (PG01) was

Keywords:

antibacterial, extract, MRSA, Psidium guajava L. identified as 3- $\beta$-hydroxylup-20 (29) - ene. The results of this research could open a new direction for the pharmaceutical industry to deal with the challenges of current situations regarding antibiotic-resistant bacteria.

\section{Giới thiệu}

Việt Nam nằm trong khu vực nhiệt đới nóng ẩm, người dân tiếp xúc nhiều với bùn đất ẩm ướt kéo dài chính là điều kiện thuận lợi cho các loài vi khuẩn, vi nấm phát triển mạnh, các bệnh về da và niêm mạc do nấm, nhiễm trùng do vi khuẩn gây ra ngày càng phổ biến và nghiêm trọng (Al-Alawi, Ryan, Flint, \& Muller, 2005). Theo Tổ chức Y tế thế giới (WHO), Việt Nam được xếp vào danh sách các nước có tỉ lệ kháng thuốc kháng sinh cao nhất thế giới (WHO, 2013). Ở Châu Âu mỗi năm, số ca nhiễm và tử vong do vi khuẩn đa kháng thường gặp nhất thường là Escherichia coli, Enterococcus faecium, Streptococcus pneumoniae, Klebsiella pneumonia, Pseudomonas aeruginosa (Francesca et al., 2015). Vì vậy, việc tìm ra nguồn thuốc mới thay thế cho các thuốc đang sử dụng trở nên cấp thiết trong đó thực vật là những nguồn đầy tiềm năng đang được quan tâm.

Ổi là cây ăn quả phổ biến, được trồng hầu như khắp các địa phương, cả vùng đồng bằng lẫn ở miền núi, trừ vùng cao trên $1500 \mathrm{~m}$. Ổi (Psidium guajava L.) chứa nhiều hợp chất phenolic ức chế phản ứng peroxid hóa trong cơ thể, do đó nó có thể ngăn chặn các bệnh mãn tính khác nhau như bệnh tiểu đường, bệnh tim mạch và ung thư. Ngoài ra, ổi rất giàu các chất chống oxy hóa, vitamin $\mathrm{C}$, kali và chất xơ. Trong một số nghiên cứu, cây ổi cho thấy hoạt tính kháng khuẩn đối với vi khuẩn gây bệnh đáng kể như Staphylococcus spp., Shigella spp., Salmonella spp., 
Bacillus spp., Escherichia coli, Clostridium spp, Pseudomonas spp (Abdeirahirn, Almadboul, Omer, \& Elegami, 2002). Năm 2005, Meckes, Calzada, Tortoriello, Gonzalez, và Martinez đã nghiên cứu ra được có hơn 20 hợp chất hoạt tính sinh học đã được chiết từ lá, thân, vỏ và rễ của cây ổi. Lá ổi được sử dụng để điều trị tiêu chảy và đau bụng. Lá ổi đã được sử dụng ở Mỹ như là kháng sinh ở dạng thuốc bôi hoặc thuốc sắc cho vết thương, loét và đau răng (Meckes et al., 2005). Hiện nay ở Việt Nam chưa có nhiều nghiên cứu được công bố về việc sử dụng các hợp chất từ lá ổi để kháng lại các vi khuẩn gây bệnh. Do đó, nghiên cứu này giúp khảo sát khả năng kháng khuẩn của nhiều loại cao chiết từ lá cây ổi, từ đó tạo tiền đề để nghiên cứu sản xuất các hợp chất kháng vi khuẩn gây bệnh trên người, đặc biệt là vi khuẩn đề kháng kháng sinh.

\section{Vật liệu và phương pháp nghiên cứu}

\subsection{Vật liệu}

Lá ổi được thu hái ở thành phố Tây Ninh được giám định khoa học tại Bộ môn Thực vật, Trường Đại học Khoa học Tự nhiên.

Các chủng vi khuẩn: Salmonella typhi ATCC 14028, Pseudomonas aeruginosa ATCC 27853, Escherichia coli ATCC 25922 được cung cấp bởi Phòng thí nghiệm Công nghệ Vi Sinh Trường Đại học Mở Thành phố Hồ Chí Minh.

Chủng S. aureus ATCC 43300 (MRSA) được cung cấp bởi công ty Nam Khoa Biotek.

\subsection{Phương pháp nghiên cúu}

\section{Quy trình chiết xuất cao durợc liệu tù lá cây ổi}

Thu nhận mẫu: chọn những mẫu lá ổi còn tươi, xanh tốt, khỏe mạnh, tăng trưởng tốt, không bị sâu bệnh, dập úng. Lá ổi đem về rửa sạch, phơi khô tự nhiên sau đó nghiền nhỏ thành bột thô và lưu trữ cho lần sử dụng kế tiếp. Bột dược liệu từ lá được chiết xuất bằng phương pháp ngâm với dung môi ethanol. Tiến hành ngâm phân đoạn bột dược liệu với dung môi và đem đi lọc chân không lấy dung dịch chiết. Dịch chiết được đem đi cô quay chân không (50 $60^{\circ} \mathrm{C}$ ) để loại hoàn toàn và thu hồi dung môi, ta thu được cao sau khi trích ly. Đem cân số cao này bằng cân phân tích. Cao thô được hòa tan với nước (tỉ lệ cao/nước là $1: 10$ ) và đem chiết lỏng - lỏng qua các hệ dung môi Hexane, Ethyl acetate và nước. Sau khi chiết lỏng - lỏng dịch chiết được cô đặc thành cao bằng cách phương pháp tương tự như trên. Đem cân các cao phân đoạn này bằng cân phân tích (Tu, 2007).

\section{Khảo sát giới hạn nhiễm khuẩn của cao chiết}

Thử giới hạn nhiễm khuẩn nhằm đánh giá số lượng vi khuẩn hiếu khí, nấm có khả năng sống lại được và phát hiện các vi khuẩn có trong cao thuốc theo dược điển Việt Nam IV. Mẫu cao chiết được hòa tan trong DMSO theo tỉ lệ $1 \mathrm{mg} / \mathrm{mL}$ và được giữ trong chai thủy tinh nhỏ đã được hấp vô trùng.

Đối với mẫu đếm tổng số nấm men - nấm mốc: dùng môi trường Sabourard dextrose agar. Đối với mẫu đếm tổng vi khuẩn hiếu khí dùng môi trường NA. Từ dung dịch mẫu thử $10^{-}$ ${ }^{1}$, pha loãng bằng dung dịch $\mathrm{NaCl} 0,85 \%$ để được nồng độ pha loãng thấp hơn $10^{-2}, 10^{-3}, .$. , cấy vào mỗi đĩa môi trường $1 \mathrm{~mL}$ mẫu thử. Rót vào mỗi đĩa petri khoảng $15 \mathrm{~mL}$ môi trường. Sau đó, 
xoay đĩa petri cùng chiều và ngược chiều kim đồng hồ vài lần để mẫu thử được trộn đều trong môi trường cấy. Để thạch đông tự nhiên, sau đó lật ngược đĩa lại và ủ trong tủ ấm $37^{\circ} \mathrm{C} / 24$ 48 giờ đối với mẫu đếm tổng số vi khuẩn hiếu khí, $28-30^{\circ} \mathrm{C} / 5$ ngày đối với mẫu đếm tổng số nấm nem - nấm mốc (Bộ Y tế, 2009).

\section{Khảo sát khả năng kháng khuẩn của cao chiết}

Để khảo sát tác động kháng khuẩn của các cao chiết từ dược liệu, chúng tôi áp dụng phương pháp khuếch tán qua giếng thạch. Sau khi thu được cao chiết chúng tôi tiến hành pha loãng cao chiết với DMSO theo tỉ lệ cao/DMSO là $100 \mathrm{mg} / \mathrm{mL}$ để khảo sát khả năng kháng khuẩn của cao chiết. Trải dịch vi khuẩn thử nghiệm (mật độ $10^{8} \mathrm{CFU} / \mathrm{ml}$ ) lên đĩa môi trường MHA. Đục lỗ đường kính $6 \mathrm{~mm}$ trong bản thạch bằng dụng cụ vô trùng. Các cao chiết được hòa tan trong dung môi dimethyl sulfoxid (DMSO) (theo tỷ lệ 1:1) và nhỏ vào mỗi giếng khoảng $70 \mu 1$. Ủ $37^{\circ} \mathrm{C} / 18$ - 24 giờ và đọc kết quả vòng kháng khuẩn. Sử dụng DMSO là đối chứng. (Rajasekaran et al., 2008)

Xác định nồng độ ức chế tối thiểu (MIC) của cao chiết với vi khuẩn gây bệnh

Nồng độ ức chế tối thiểu (Minimum Inhibitory Concentration - MIC) là nồng độ cao chiết (hoặc kháng sinh) thấp nhất mà tại đó cao chiết có khả năng ngăn chặn sự tăng trưởng của vi sinh vật. Để xác định MIC của các cao chiết từ dược liệu với các vi sinh vật chúng tôi áp dụng phương pháp pha loãng trong môi trường thạch (CLSI, 2010). Từ dung dịch gốc có nồng độ $100 \mathrm{mg} / \mathrm{mL}$, cao chiết thử nghiệm được pha loãng với DMSO theo cấp số nhân thành các nồng độ liên tiếp $1 / 2,1 / 4,1 / 8,1 / 16,1 / 32,1 / 64$. Sau đó trộn $2,5 \mathrm{~mL}$ dung dịch cao chiết đã pha vào $22,5 \mathrm{~mL}$ thạch MHA. Tiến hành nhỏ $2 \mu \mathrm{L}$ dịch vi khuẩn (có nồng độ $10^{6}$ tế bào/mL) lên đĩa thạch MHA có chứa nồng độ cao chiết thử nghiệm, ủ trong $37^{\circ} \mathrm{C} / 24 \mathrm{~h}$ (Kalita, Saikia, Sindagi, \& Anmol, 2012).

Điều chế các phân đoạn tù̀ cao etyl axetat bằng phương pháp sắc ký cột

Đem toàn bộ cao etyl axetat thu nhận được trộn với silica gel (tỉ lệ 5:50). Cho hết hỗn hợp đó vào cột và rót dung môi giải ly vào. Sau khi hoàn tất việc nạp mẫu cho một ít bông gòn ở bên trên mẫu chất để ổn định, tiếp tục châm dung môi giải ly vào. Thu cao phân đoạn với các hệ dung môi hexane: etyl axetat $(75: 25 ; 50: 50 ; 25: 75 ; 0: 100$; etyl axetat: methanol = 90:10). Thực hiện khảo sát khả năng kháng khuẩn đối với các phân đoạn thu được.

Xác định cấu trúc hợp chất tụ̣ nhiên trong lá cây ổi

Đem hợp chất thu được thực hiện sắc ký cột với hệ dung môi hexane: ethyl axetat để tiếp tục tinh sạch hợp chất đó. Sau mỗi lần lên cột thu được sản phẩm đều tiến hành thử hoạt tính kháng khuẩn. Tiến hành xác định cấu trúc hóa học của hợp chất có họat tính kháng khuẩn mạnh nhất bằng phương pháp giải phổ ${ }^{1} \mathrm{H},{ }^{13} \mathrm{C}-\mathrm{NMR}$.

\section{Kết quả và thảo luận}

\section{cây ổi}

Khảo sát ảnh hưởng của dung môi chiết đến khối lượng cao chiết thu được từ lá

Lượng bột dược liệu sử dụng để chiết với ethanol là 4kg. Sau khi bốc hơi dung môi để có cao đặc, thu được 1,84kg cao (hiệu suất 46\%). 
Sau đó, đem toàn bộ cao chiết thu được thực hiện chiết lỏng - lỏng với các loại dung môi là nước, ethyl axetat, hexane. Kết quả cho thấy dung môi nước cho khối lượng cao chiết cao nhất là $700 \mathrm{~g}$ với hiệu suất thu hồi là $17,5 \%$ (Bảng 1 ). Từ kết quả đó cho thấy dung môi có tính phân cực cao thì sẽ thu được khối lượng cao chiết cao hơn.

\section{Bảng 1}

Hiệu suất thu cao từ các loại dung môi chiết

\begin{tabular}{|c|c|c|}
\hline Dung môi & Khối lượng cao & Hiệu suất \% \\
\hline Nước & $700 \mathrm{~g}$ & 17,5 \\
\hline Ethyl axetat & $500 \mathrm{~g}$ & 12,5 \\
\hline Hexane & $155,2 \mathrm{~g}$ & 3,88 \\
\hline
\end{tabular}

Nguồn: Kết quả phân tích dữ liệu của nhóm nghiên cứu

\section{Xác định độ nhiễm khuẩn của cao chiết}

Cao chiết sau khi trích ly ta tiến hành thử giới hạn nhiễm khuẩn nhằm đánh giá số lượng vi khuẩn, nấm có trong cao chiết từ lá cây ổi. Kết quả mẫu cao chiết không bị nhiễm nấm men, nấm mốc, tổng số vi khuẩn hiếu khí, nằm trong khoảng giới hạn cho phép của dược điển Việt Nam IV (Bộ Y tế, 2009) là không quá 5 x 10 $0^{4} \mathrm{CFU} / \mathrm{g}$ (Bảng 2).

Bảng 2

Kết quả số lượng nấm và vi khuẩn sống có trong cao chiết

\begin{tabular}{|c|c|c|}
\hline Cao chiết từ dung môi & $\begin{array}{c}\text { Tổng số vi khuẩn hiếu khí } \\
(\mathbf{C F U} / \mathbf{g})\end{array}$ & $\begin{array}{c}\text { Tổng số nấm men - nấm } \\
\text { mốc }(\mathbf{C F U} / \mathbf{g})\end{array}$ \\
\hline Nước & $5,18 \times 10^{2}$ & - \\
\hline Etyl axetat & $6,86 \times 10^{2}$ & - \\
\hline Hexane & $1,95 \times 10^{3}$ & - \\
\hline
\end{tabular}

Ghi chú (-): ít hơn 10 vi khuẩn hiếu khí, nấm men, nấm mốc trong $1 \mathrm{~g}$ cao thuốc

Nguồn: Kết quả xử lý từ dữ liệu điều tra

\section{Kết quả định tính khả năng kháng khuẩn}

Từ Bảng 3, Hình 1 cho thấy có sự khác biệt có ý nghĩa về đường kính kháng khuẩn của các cao chiết bằng các dung môi khác nhau. Cao nước và cao etyl acetat có khả năng kháng với cả 4 chủng vi khuẩn gây bệnh, trong đó cao ethyl axetat có khả năng kháng khuẩn cao nhất và kháng cao nhất với MRSA lần lượt là $31,67 \pm 1,52 \mathrm{~mm}$, tiếp theo là cao nước và kháng MRSA cao nhất là $22,33 \pm 0,57 \mathrm{~mm}$. Cao hexane không có khả năng kháng khuẩn.

\section{Bảng 3}

Đường kính vòng vô khuẩn $(\mathrm{mm})$ của các loại cao chiết

\begin{tabular}{|c|c|c|c|c|c|}
\hline STT & Loại cao chiết & E.coli & S.typhi & P.aeruginosa & MRSA \\
\hline 1 & Nước & $\begin{array}{c}20,33 \\
\pm 1,62^{\mathrm{b}}\end{array}$ & $\begin{array}{c}15,67 \\
\pm 0,33^{\mathrm{b}}\end{array}$ & $15,33 \pm 0,57^{\mathrm{b}}$ & $\begin{array}{c}22.33 \pm \\
0,57^{\mathrm{b}}\end{array}$ \\
\hline
\end{tabular}




\begin{tabular}{|c|c|c|c|c|c|}
\hline STT & Loại cao chiết & E.coli & S.typhi & P.aeruginosa & $M R S A$ \\
\hline 2 & Etyl axetat & $\begin{array}{c}22,67 \pm \\
1,62^{\mathrm{a}}\end{array}$ & $\begin{array}{c}18,00 \pm \\
1,00^{\mathrm{a}}\end{array}$ & $17,67 \pm 1,15^{\mathrm{a}}$ & $\begin{array}{c}31.67 \pm \\
1,52^{\mathrm{a}}\end{array}$ \\
\hline 3 & Hexane & 0 & 0 & 0 & 0 \\
\hline
\end{tabular}

Nguồn: Kết quả phân tích dữ liệu của nhóm nghiên cứu

Theo nghiên cứu của Geidam, Ambali, và Onyeyili (2007), cao ethyl axetat có khả năng kháng MRSA, S.typhi, E.coli, trong đó: kháng với MRSA là 7,0mm, 8,0mm, 10,0mm tương ứng với nồng độ cao/dung môi 100, 200 và 400mg/mL.(Geidam et al., 2007).

Tương tự, theo nghiên cứu của Alamin, Samia, Alqurashi, và Elsheikh (2016), cao ethyl axetat có khả năng kháng MRSA và E.coli, trong đó kháng với MRSA là $11,50 \pm 0,65 \mathrm{~mm}$, $12,25 \pm 0,25 \mathrm{~mm}, 12,75 \pm 0,48 \mathrm{~mm}, 13,50 \pm 0,50 \mathrm{~mm}$ tương ứng với nồng độ cao/dung môi là $300,400,500,600 \mathrm{mg} / \mathrm{mL}$. (Alamin et al., 2016). Qua đó cho thấy, kết quả nghiên cứu của chúng tôi có sự tương đồng với các nghiên cứu trên, mặc khác kết quả khả năng kháng khuẩn của chúng tôi cao hơn nhiều so với các nhóm tác giả.

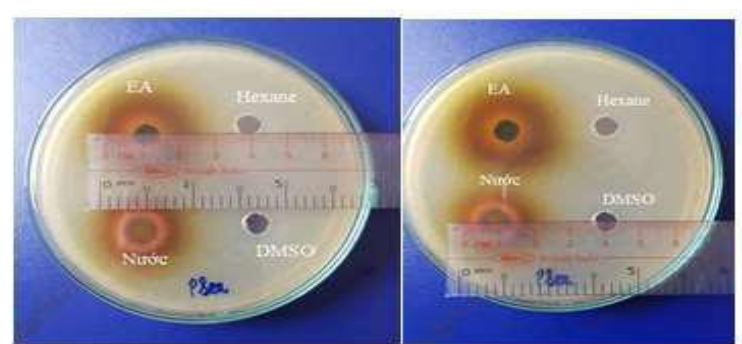

A

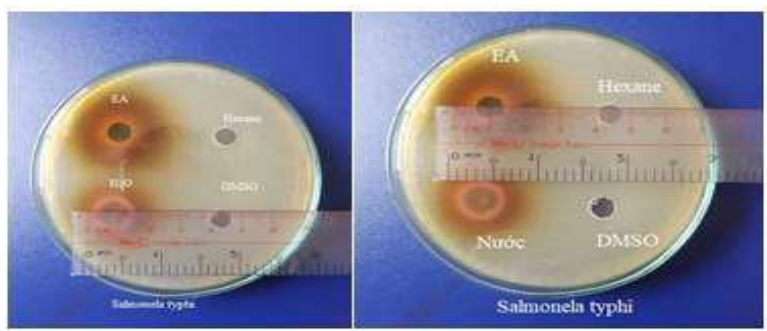

$\mathrm{C}$

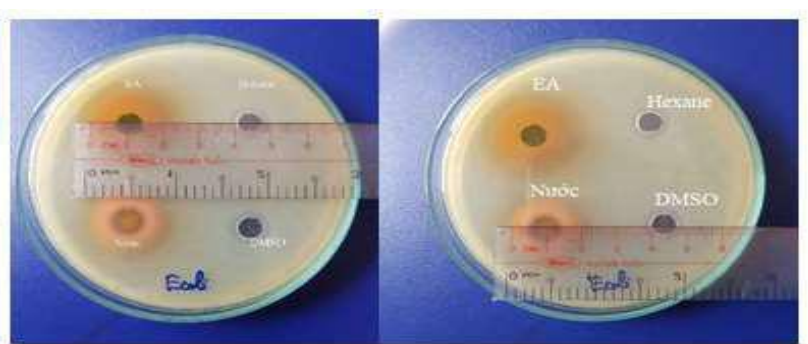

B

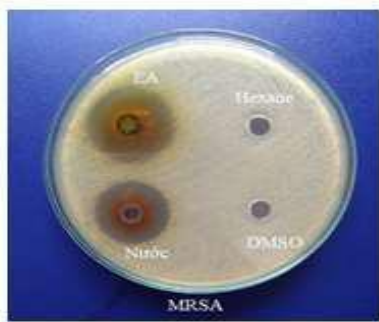

$\mathrm{D}$

Hình 1. Đường kính vòng kháng khuẩn của các loại cao chiết

P. aeruginosa, B. E.coli, C. S.typhi, D. MRSA

\section{Kết quả xác định nồng độ ức chế tối thiểu (MIC) của cao chiết}

Tiến hành hòa tan mẫu cao chiết ethyl axetat trong DMSO ở nồng độ thử là $100 \mathrm{mg} / \mathrm{mL}$. Kết quả cao chiết với ethyl axetat có tác động ức chế MRSA, E. coli và S.typhi ở nồng độ tối thiểu (MIC) là $1 / 128$ tương ứng nồng độ $1,5625 \mathrm{mg} / \mathrm{mL}$ và có tác động ức chế $P$. aeruginosa ở nồng độ tối thiểu (MIC) là 1/256 tương ứng nồng độ $0,78 \mathrm{mg} / \mathrm{mL}$ (Bảng 4 ). 


\section{Bảng 4}

Nồng độ ức chế tối thiểu (MIC) của cao chiết $(\mathrm{mg} / \mathrm{mL})$

\begin{tabular}{|c|c|c|c|c|c|c|c|c|}
\hline \multirow{2}{*}{ Chủng vi khuẩn } & \multicolumn{6}{|c|}{ Nồng độ ức chế tối thiểu (MIC) (mg/mL) của cao Ethyl axetat } \\
\cline { 2 - 9 } & $\mathbf{5 0}$ & $\mathbf{2 5}$ & $\mathbf{1 2 , 5}$ & $\mathbf{6 , 2 5}$ & $\mathbf{3 , 1 2 5}$ & $\mathbf{1 , 5 6 2 5}$ & $\mathbf{0 , 7 8}$ & $\mathbf{0 , 3 9}$ \\
\hline E. coli & - & - & - & - & - & - & + & + \\
\hline S.typhi & - & - & - & - & - & - & + & + \\
\hline P. aeruginosa & - & - & - & - & - & - & - & + \\
\hline MRSA & - & - & - & - & - & - & + & + \\
\hline
\end{tabular}

(-): vi khuẩn không mọc

(+): vi khuẩn có mọc

Nguồn: Kết quả phân tích dữ liệu của nhóm nghiên cứu

Theo nghiên cứu của Geidam và cộng sự (2007), nồng độ ức chế tối thiểu của cao ethyl axetat với MRSA, S.typhi là $12,5 \mathrm{mg} / \mathrm{mL}$ và E.coli là $6,25 \mathrm{mg} / \mathrm{mL}$ (Geidam et al., 2007). Theo nghiên cứu của Alamin và cộng sự (2016), nồng độ ức chế tối thiểu của cao ethyl axetat với MRSA, E.coli lần lượt là $12,5 \mathrm{mg} / \mathrm{mL}$ và $25 \mathrm{mg} / \mathrm{mL}$ (Alamin et al., 2016). Hiện nay, ở nước ta chưa có nhiều công trình nghiên cứu về khả năng kháng khuẩn của cao chiết lá cây ổi, do đó kết quả này cho thấy cao chiết lá cây ổi có khả năng kháng một số vi khuẩn gây bệnh, đặc biệt là kháng vi khuẩn MRSA - một vấn đề y tế toàn cầu, là một thách thức trong điều trị. Hiện nay, MRSA đang gia tăng về tần suất và hiện hữu ở nhiều cơ sở y tế, cộng đồng. Qua đó, đã thấy được một kết quả khả quan về khả năng kháng vi khuẩn kháng thuốc và tiềm năng ứng dụng của cao chiết lá cây ổi.

\section{Điều chế và khảo sát hoạt tính kháng khuẩn của các cao phân đoạn cao ethyl axetat}

Từ Bảng 5 cho thấy phân đoạn 1 có khối lượng cao nhất là $79,4 \mathrm{~g}$. Tiếp theo là phân đoạn 4 , phân đoạn 3 , phân đoạn 5 và thấp nhất là phân đoạn 2 là $5,2 \mathrm{~g}$.

\section{Bảng 5}

Khối lượng của các phân đoạn thu được (g)

\begin{tabular}{|c|c|c|}
\hline Phân đoạn & Hệ dung môi hexane : ethyl axetat & Khối lưọ̆ng (g) \\
\hline 1 & $75: 25$ & 79,4 \\
\hline 2 & $50: 50$ & 5,2 \\
\hline 3 & $25: 75$ & 14,1 \\
\hline 4 & $100 \%$ ethyl & 15 \\
\hline 5 & Ethyl : methanol $=90: 10$ & 7,3 \\
\hline
\end{tabular}

Nguồn: Kết quả phân tích dữ liệu của nhóm nghiên cứu

Thực hiện khảo sát khả năng kháng khuẩn đối với 5 phân đoạn này và kết quả được thể hiện Bảng 6 cho thấy phân đoạn 4 cho kết quả kháng khuẩn cao nhất và kháng cao nhất với 
MRSA là 25,33 $\pm 0,58 \mathrm{~mm}$, do đó chọn phân đoạn 4 để tiếp tục tiến hành nghiên cứu thành phần hóa học.

\section{Bảng 6}

Đường kính vòng vô khuẩn $(\mathrm{mm})$ của các phân đoạn

\begin{tabular}{|c|c|c|c|c|}
\hline Loại cao chiết & E.coli & S.typhi & P.aeruginosa & MRSA \\
\hline Phân đoạn 1 & $10,33 \pm 0,33^{\mathrm{c}}$ & $9,00 \pm 1,0^{\mathrm{c}}$ & 0 & $22,33 \pm 0,58^{\mathrm{b}}$ \\
\hline Phân đoạn 2 & $11,33 \pm 0,33^{\mathrm{c}}$ & $12,33 \pm 0,58^{\mathrm{b}}$ & 0 & $20,33 \pm 0,58^{\mathrm{c}}$ \\
\hline Phân đoạn 3 & $16,00 \pm 1,0^{\mathrm{b}}$ & $14,67 \pm 0,58^{\mathrm{a}}$ & $18,33 \pm 0,58^{\mathrm{b}}$ & $24,33 \pm 1,53^{\mathrm{a}}$ \\
\hline Phân đoạn 4 & $17,67 \pm 0,33^{\mathrm{a}}$ & $16,00 \pm 1,0^{\mathrm{a}}$ & $19,67 \pm 0,58^{\mathrm{a}}$ & $25,33 \pm 0,58^{\mathrm{a}}$ \\
\hline Phân đoạn 5 & $11,33 \pm 0,33^{\mathrm{c}}$ & $11,33 \pm 0,58^{\mathrm{b}}$ & $12,33 \pm 1,15^{\mathrm{c}}$ & $14,67 \pm 0,58^{\mathrm{d}}$ \\
\hline
\end{tabular}

Nguồn: Kết quả phân tích dữ liệu của nhóm nghiên cứu

\section{Xác định cấu trúc hợp chất tự nhiên trong lá cây ổi}

Đem phân đoạn 4 tiếp tục chạy sắc ký cột với hệ dung môi hexane: ethyl axetat thu được 1 lượng hợp chất. Đem hợp chất đó tiếp tục chạy sắc ký cột với hệ dung môi hexane: ethyl axetat để tinh sạch hợp chất đó. Sau khi thu nhận hợp chất dưới dạng tinh thể hình kim màu trắng, kí hiệu là $\mathrm{PG} 01$ và tiến hành đi xác định cấu trúc bằng phương pháp giải phổ ${ }^{1} \mathrm{H},{ }^{13} \mathrm{C}$ NMR.

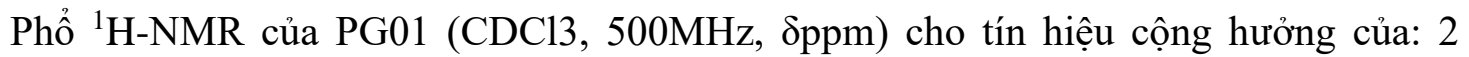
proton olefin của nhóm exocyclic methylene ở $\delta \mathrm{H} 4,57(1 \mathrm{H}, d d, J=1,5 \& 2,0 \mathrm{~Hz}, \mathrm{H}-29 \mathrm{a})$ và $4,69(1 \mathrm{H}, d, J=2,0 \mathrm{~Hz}, \mathrm{H}-29 \mathrm{~b})$; 1 proton oxymethine ở $\delta \mathrm{H} \mathrm{3,19}(1 \mathrm{H}, d d, J=5,0 \& 11,5 \mathrm{~Hz}, \mathrm{H}-$ 3); proton của 7 nhóm methyl ở $\delta \mathrm{H} 0,97(3 \mathrm{H}, s, \mathrm{H}-23), 0,76(3 \mathrm{H}, s, \mathrm{H}-24), 0,83(3 \mathrm{H}, s, \mathrm{H}-25)$, $1,03(3 \mathrm{H}, s, \mathrm{H}-26), 0,95(3 \mathrm{H}, s, \mathrm{H}-27), 0,79$ (3H, $s, \mathrm{H}-28)$ và 1,68 (3H, $s, \mathrm{H}-30)$.

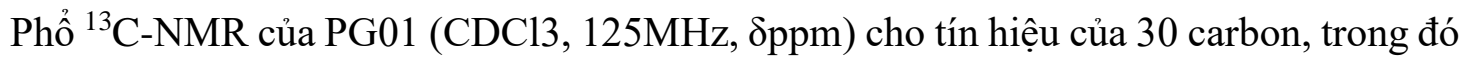
có 2 carbon olefin ở $\delta \mathrm{C} 151,0(\mathrm{C}-20)$ và 109,3 (C-29), 1 carbon oxymethine ở $\delta \mathrm{C} 79,0(\mathrm{C}-3)$ và 7 carbon methyl ở $\delta \mathrm{C} 28,0$ (C-23), 15,4 (C-24), 16,0 (C-25), 16,1 (C-26), 14,6 (C-27), 18,0 (C28) và 19,3 (C-30); giúp xác nhận $\mathrm{PG01}$ có khung sườn là 3 -hydroxylup-20(29)-ene (Beserra et al., 2018).

Dựa trên dữ liệu phổ ${ }^{1} \mathrm{H},{ }^{13} \mathrm{C}-\mathrm{NMR}$ và so sánh với tài liệu (Beserra et al., 2018), cấu trúc của PG01 được xác định là 3 -hydroxylup-20(29)-ene (Lupeol). 


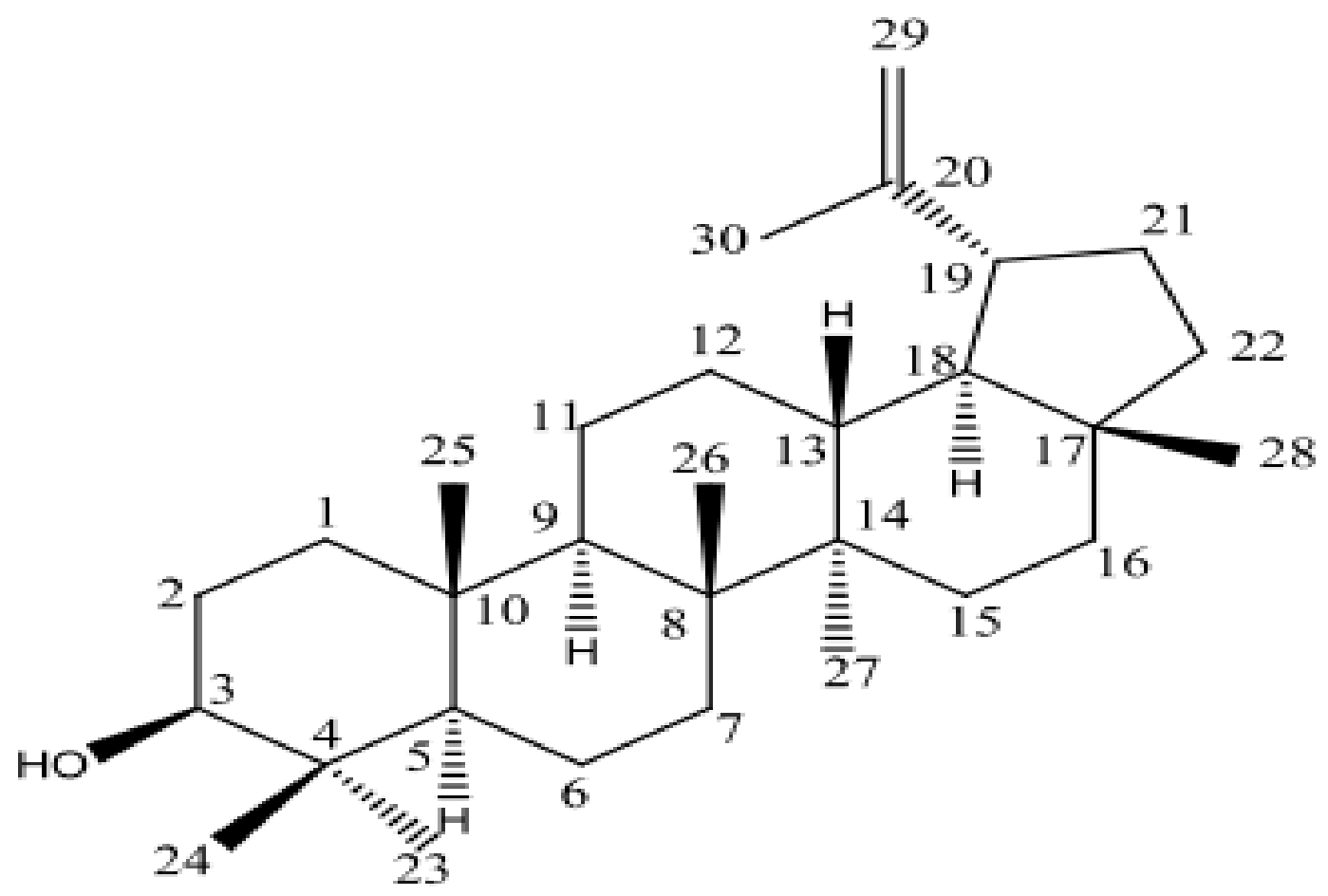

Hình 2. Cấu trúc hoá học của PG01

Theo một số nghiên cứu cho thấy lupeol được phân lập từ các cây khác có khả năng ức chế sự phát triển của một số loại vi khuẩn và nấm (Ahmed et al., 2010; Shai, McGaw, Aderogba, Mdee, \& Eloff, 2008). Trong nghiên cứu của Jackie, Von Atte, Jimmy, Jussi, và Carina (2016), lupeol được phân lập từ vỏ thân cây $C$. macrostachyus bằng cách chiết xuất ethyl acetate có khả năng kháng một số mầm bệnh quan trọng ở người $E$. coli, S. typhi, K. pneumoniae và $C$. albicans (Jackie et al., 2016). Theo nghiên cứu của Saleem (2009), hợp chất Lupeol đã được chứng minh là thể hiện các hoạt động dược lý khác nhau trong điều kiện in-vitro và in-vivo. Chúng bao gồm hoạt động có lợi như: chống viêm, ung thư, viêm khớp, tiểu đường, bệnh tim, nhiễm độc thận và độc tính gan. Lupeol đã được nghiên cứu rộng rãi về tác dụng ức chế viêm trong điều kiện in-vitro và trên mô hình động vật (Saleem, 2009). Theo nghiên cứu của Siddique và Saleem (2011), hợp chất Lupeol hoạt động dược lý chống lại các tình trạng bệnh khác nhau. Chúng bao gồm các tình trạng như viêm, viêm khớp, tiểu đường, bệnh tim mạch, rối loạn thận, nhiễm độc gan, nhiễm trùng vi khuẩn và ung thư. Lupeol đã được chứng minh có khả năng ức chế các phân tử đóng vai trò chính trong sự phát triển của các bệnh khác nhau ở người (Siddique \& Saleem 2011).

\section{Kết luận}

Ở nghiên cứu này, chúng tôi thu được cao ethyl axetat có khả năng kháng khuẩn cao nhất và kháng cao nhất với MRSA lần lượt là $31,67 \pm 1,52 \mathrm{~mm}$. Cao chiết với ethyl axetat có tác động ức chế MRSA, $E$. coli và S.typhi ở nồng độ tối thiểu (MIC) là $1 / 128$ tương ứng nồng độ $1,5625 \mathrm{mg} / \mathrm{mL}$ và có tác động ức chế $P$. aeruginosa ở nồng độ tối thiểu (MIC) là $1 / 256$ tương 
ứng nồng độ $0,78 \mathrm{mg} / \mathrm{mL}$. Dựa trên dữ liệu phổ $1 \mathrm{H}, 13 \mathrm{C}-\mathrm{NMR}$ và so sánh với tài liệu (Beserra et al., 2018), cấu trúc của PG01 được xác định là 3 $\beta$-hydroxylup-20(29)-ene. Kết quả của đề tài có thể sẽ mở ra một hướng phát triển mới cho ngành Dược cũng như các công ty nghiên cứu điều chế thuốc kháng sinh trước những thách thức của tình hình vi khuẩn đề kháng kháng sinh hiện nay. Mặt khác sẽ giúp cho ngành dược liệu y học cổ truyền được chú ý và phát triển mạnh mẽ hơn nữa.

\section{Tài liệu tham khảo}

Abdeirahirn, S. I., Almadboul, A. Z., Omer, M. E. A., \& Elegami, A. (2002). Antimicrobial activity of Psidium guajava L. Fitoterapia, 73(7/8), 713-715.

Ahmed, Y., Sohrab, M. H., Al-Reza, S. M., Tareq, F. S., Hasan, C. M., \& Sattar, M. A. (2010). Antimicrobial and cytotoxic constituents from leaves of Sapium baccatum. Food and Chemical Toxicology, 48(2), 549-552.

Al-Alawi, A., Ryan, C. F., Flint, J. D., \& Muller, N. L. (2005). Aspergillus-related lung disease. Canadian Respiratory Journal, 12(7), 377-387.

Alamin, M. A., Samia, M. A., Alqurashi, A. M., \& Elsheikh, A. S. (2016). Bactericidal activity of Psidium guajava leaves against some pathogenic microbes. IOSR Journal of Dental and Medical Sciences, 15(3), 61-70.

Beserra, F. P., Xue, M., de Azevedo, M. G. L., Rozza, A. L., Pellizzon, C. H., \& Jackson, C. J. (2018). Lupeol, a pentacyclic triterpene, promotes migration, wound closure, and contractile effect in vitro: Possible involvement of PI3K/Akt and p38/ERK/MAPK pathways. Molecules, 23(11), Article 2819.

Bộ Y tế. (2009). Dược điển Việt Nam 4 [Vietnamese pharmacopoeia 4]. Hanoi, Vietnam: Nhà xuất bản Hà Nội.

CLSI. (2010). Methods for antimicrobial dilution and disk susceptibility testing of infrequently isolated or fastidious bacteria: Approved guidelines (2nd ed.). CLSI document M45-A2. Wayne, PA: Clinical and Laboratory Standards Institute.

Francesca, I., Doroudchi, M. M., Ismail, N., Carreno, A., Griner, E., \& Lim, M. A. (2015). Registered report: Interactions between cancer stem cells and their niche govern metastatic colonization. Elife, 4, 1-14.

Geidam, Y. A., Ambali, A. G., \& Onyeyili, P. A. (2007). Phytochemical screening and antibacterial properties of organic solvent fractions of Psidium guajava aqueous leaf extracts. International Journal of Pharmacology, 3(1), 68-73.

Jackie, K. O., Von Atte, W., Jimmy, O., Jussi, K., \& Carina, T. K. (2016). Antimicrobial activity of Croton macrostachyus stem bark extracts against several human pathogenic bacteria. Journal of Pathogens, 2016, Article 1453428. doi:10.1155/2016/1453428

Kalita, D., Saikia, J. C. H., Sindagi, A. S., \& Anmol, G. K. (2012). Antimicrobial activity of leaf extract of two medicinal plants of Boghora Hill (Morigaon) Assam against human 
pathogens. The Bioscan an International Quarterly Journal of Life Sciences, 7(2), 271274.

Meckes, M., Calzada, F., Tortoriello, B. J., Gonzalez, J. L., \& Martinez, M. (2005). Terpenoids isolated from Psidium guajava hexane extract with depressant activity on central nervous system. Phytotherapy Research, 10(7), 600-603.

Rajasekaran, C., Meignanam, E., Vijayakumar, V., Kalaivani, T., Ramya, S., Premkumar, N., ... Jayakumararaj, R. (2008). Investigations on antibacterial activity of leaf extracts of Azadirachta indica A.Juss (Meliaceae): A traditional medicinal plant of India. Ethnobotanical Leaflets, 12, 1213-1217.

Saleem, M. (2009). Lupeol, a novel anti-inflammatory and anti-cancer dietary triterpene. Cancer Letters, 285(2), 109-115. doi:10.1016/j.canlet.2009.04.033

Shai, L. J., McGaw, L. J., Aderogba, M. A., Mdee, L. K., \& Eloff, J. N. (2008). Four pentacyclic triterpenoids with antifungal and antibacterial activity from Curtisia dentata (Burm.f) C.A. Sm. leaves. Journal of Ethnopharmacology, 119(2), 238-244.

Siddique, H. R., \& Saleem, M. (2011). Beneficial health effects of lupeol triterpene: A review of preclinical studies. Life Sciences 88(7-8), 285-293. doi:10.1016/j.lfs.2010.11.020

Tu, K. M. (2007). Kỹ thuật sản xuất dược phẩm [Pharmaceutical production techniques]. Hanoi, Vietnam: NXB Y học.

World Health Organization (WHO). (2013). World Health Statistics 2013. Retrieved March 30, 2018 , from https://www.who.int/gho/publications/world_health_statistics/EN_WHS2013_Full.pdf 